\title{
AS PROPRIEDADES DO VERBO E A INVERSÃO
}

\begin{abstract}
Mikotajczak Sylwia, As propriedades do verbo $e$ a inversāo [Verb properties and inversion]. Studia Romanica Posnaniensia, Adam Mickiewicz University Press, Poznań, vol. XXXI: 2004, pp. 377-384. ISBN 83-232-1353-4, ISSN 0137-2475.
\end{abstract}

The article aims to present basic verb properties engaged in the process of inversion. In Portuguese, that is a language with a null-subject parameter, the inversion seems to be more related to the proper verb rather than subject characteristics. We differentiate semantic features of a verb which categorise the verbs expressing movement, 'entry in the scene', and psychological ones as the classes of verbs prompted to inversion. The semantic features of the differentiated categories relate to syntactic inversion favouring intransitive and inaccusative verbs. Last but not least, the information and communicative factors place the verbs in the sentence initial position, opposite to the subject rhematic elements.

\section{INTRODUÇÃO}

Todos reconhecemos que a ordem das palavras na frase obedece a certas regras sintáctico-semânticas estritas. A regra principal e universal é a organização dos elementos segundo a ordem linear dependente das relações temporais e espaciais, ou seja, cada elemento simples pode ser ligado directamente apenas a dois elementos, um em anteposição e outro em posposição. Temos que admitir que isso já causa bastantes limitações construtivas e o grau desta limitação aumenta com toda a gama das regras obrigatórias, sintáctico-semânticas, mais ou menos individuais.

As mesmas regras limitativas aplicam-se ao mecanismo da inversão, e a facilidade com que se a emprega. Portanto, algumas línguas parecem revelar neste campo menos limitações do que outras. Observa-se que nas línguas românicas, denominadas línguas de ordem livre el grado de gramaticalización es menor que el que encontramos en lenguas de orden rígido (como el inglés) (López Meirama, 1997: 13). Esta tese não poucas vezes vai acompanhada por os exemplos como os seguintes: 
1a. O Pedro fez o trabalho.

1b. O trabalho fez o Pedro.

1c. Fez o trabalho o Pedro.

1d. Fez o Pedro o trabalho.

2a. Peter did the job.

2b. *The job did Peter.

2c. *Did the job Peter.

2d. *Did Peter the job.

Os exemplos do português, embora uns deles, soem pouco natural (especialmente os dois últimos), são aceitáveis, e as reordenadas frases inglesas resultam agramaticais. Esta liberdade é, em grande extensão, um produto do carácter flexivo das línguas românicas, o que, em consequência, dá uma mobilidade do elemento que funciona como sujeito.

\section{ARGUMENTOS A FAVOR DA IMPORTÂNCIA DO VERBO NO PROCESSO DA INVERSÃO EM PORTUGUÊS}

Nós, no entanto, podemos tomar outra perspectiva, dizendo que tal carácter da língua dá mais liberdade ao verbo. O que queríamos apontar com isso é que embora o papel do SN e do SV tenham igual importância no processo da inversão, assim como os dois são estruturalmente independentes e nenhum deles é dominado pelo outro, ao observar as propriedades sintácticas da língua portuguesa podemos indicar, como mais relevante, o factor do tipo de verbo. Um dos argumentos para defender este ponto de vista recai no facto do português ser uma língua de sujeito nulo, que significa que em muitas frases o sujeito não tem realizaçāo lexical, apresenta-se sintacticamente, então como uma categoria vazia. É a existência da flexão verbal que permite a falta do sujeito (logicamente, o elemento optativo é menos importante).

Por outro lado há certos verbos que causam, pelas suas características semântico-sintácticas, a ordem inversa VS, sem deixar lugar para outra possibilidade - por exemplo, as frases presentativas do tipo:

\section{Há muitos carros na rua.}

Há frases nas quais a posposição do sujeito é perfeitamente possível e ainda mais natural. É, por exemplo, o caso das frases indicadas por M. Brito (1980/81: 198) com os verbos de entrada em cena (vir, chegar, etc.):

\section{Chegaram os delegados alemães.}

Assim, se o verbo é um elemento tão essencial no processo da inversão, facto que tentámos evidenciar, quais serão as suas propriedades relevantes neste processo? 


\section{AS PROPRIEDADES DO VERBO E A INVERSÃO}

\subsection{A CARACTERISTICA SEMÂNTICA DO VERBO}

Antes de procurarmos construir uma explicação para a correlação entre o verbo e a ordem inversa VS, temos que mostrar uma classificação do verbo segundo as suas propriedades semânticas. Baseando-nos na classificação de Morales (apud Gawełko, 1995: 185) podemos apresentar as classes semânticas do verbo no seguinte quadro:

\begin{tabular}{|l|l|}
\hline \multicolumn{1}{|c|}{ Semântica } & \multicolumn{1}{c|}{ Verbo } \\
\hline Existencial & existir, morrer, ficar, estar, etc. \\
\hline Movimento & andar, correr, sair, etc. \\
\hline Psicológico & assustar, entristecer, interessar, gostar, etc. \\
\hline Percepcão & pensar, conhecer, etc. \\
\hline Expressão & explicar, declarar, afirmar, etc. \\
\hline Comportamento & trabalhar, dormir, etc. \\
\hline Posse & guardar, etc. \\
\hline Entrada em cena & aparecer, nascer, vir, chegar, entrar, etc. \\
\hline
\end{tabular}

No entanto, temos modificado um pouco a classificação de Morales. De propósito temos acrescentado outra classe de verbos, os quais ele inclui nos grupos, ora dos verbos existenciais (aparecer, nascer), ora nos de movimento (vir, entrar, chegar), colocando-os na categoria dos verbos de entrada em cena ${ }^{1}$. Assim como os verbos aparecer, nascer identificam-se mais com a ideia de aparição do que com o estado permanente de existir. Da mesma maneira, os verbos vir, entrar e chegar não implicam tanto a acção de mover-se como a detenção desta acção, ligada ao seu resultado, que é aparição no lugar. Cremos que esta observação explica a presença desta classe de verbos, que além disso aparecem em número considerável nas frases, nas quais a ocorrência do sujeito posposto é perfeitamente possível, senão obrigatória:

5a. Os meninos chegaram.

5b. Chegaram os meninos.

A frase (5b) com a posposição do sujeito é mais natural, e em alguns contextos comunicativos será a única possível.

As construções compostas dos verbos de entrada em cena introduzem novos argumentos, e como o novo normalmente coloca-se no final da frase, a ordem VS é perfeitamente gramatical e mais natural em certos contextos discursivos. Porém, em frases com verbos de entrada em cena e sujeitos indefinidos, como (6) a posposição do sujeito é obrigatória:

\section{Apareceram controvérsias.}

'Apoiado pela classificaçāo de Sgall e Dahl (apud Brito, 1980/81: 197). 
A ordenação de constituintes depende, em grande extensão, da distribuição da informação na frase. De facto, o sujeito perde o seu significado temático, enquanto o verbo sofre um processo de forte gramaticalização que o converte numa simples marca do sujeito indefinido. Apesar disso, aparece muitas vezes, outro predicado que é informativamente mais relevante. Este predicado pode ter uma forma da infinitiva ou relativa, por exemplo:

\section{Apareceram controvérsias que quebraram o silêncio.}

O verbo sinaliza o aparecimento de uma coisa, o efeito dela, enquanto, o que interessa mais é expresso pelo segundo predicado da frase relativa.

Do ponto de vista semântico, os verbos de entrada em cena com sujeitos indefinidos inversos expressam o aparecimento de individuais designados pelos elementos nominais, e são, em realidade, um exemplo das expressões téticas (não têm tema).

Observando os exemplos das inversões, vemos que existe um certo cruzamento entre o tipo de verbo e os traços do sujeito. Devem existir correlações significativas relacionadas principalmente aos traços de definitude entre construções intransitivas e inacusativas. À medida que o sujeito é marcado por traços negativos de definitude (e de especificidade) cresce o percentual da ordem VS em certos contextos de inacusatividade; quando, porém, o sujeito é marcado por traços positivos, a preferência é para a ordem SV (excepto em contextos existenciais). Essa correlação mostra que o grupo de factores dos traços semânticos do sujeito não tem relevância independente. As possibilidades da ordem VS manifestam-se com menos restrições semânticas, em especial quando o sujeito é marcado com traços [-definido] e [-específico].

Assim, o carácter semântico do verbo e do sujeito, condiciona a inversão. Já sabemos que as características do verbo favorecem certas construções. Por exemplo, o factor semântico dos verbos de entrada em cena é o carácter geral do verbo, a própria ideia de aparição. Observamos que verbos deste grupo em muitos casos provocam inversão, mas não é uma regra universal. O factor semântico costuma coincidir com o outro catalisador da inversão - factor informativo.

\subsection{OS MOTIVOS COMUNICATIVO-INFORMATIVOS DA INVERSÃO}

Não deixa dúvida nenhuma dizer que a estrutura informativa influi a ordem dos constituintes da frase. Assim, a distribuição da informação pode explicar o emprego da inversão em determinado contexto discursivo. Em outras palavras, escolher-se-á a ordem directa ou a VS conforme a situação. Imaginemos, por exemplo, a seguinte situação: $O$ Marco tem estado doente. Não está presente há uns dias e os amigos sentem a sua falta. Na turma, há também os que conhecem o Marco, mas a quem ele é indiferente. Suponhamos, então, as seguintes reacções:

8a. Oh!... Vem ali o Marco!

8b. O Marco vem ali. 
Geralmente, os amigos mais próximos do Marco pronunciavam a frase (8a). Iniciavam-na por vem, porque, naquele momento, o que lhes tocou mais a sensibilidade não foi o Marco em pessoa, mas o mover-se já com saúde, isto é, o vir - o vir já pelo seu pé. E então saiu-lhes muito naturalmente a frase (8a), começada por vem, com o verbo em primeiro lugar, o de mais evidência.

Mas o outro falante, para quem o Marco era como qualquer pessoa, possivelmente nem se lembrava de ele ter estado doente. Saiu-lhe, então, a frase (8b), na ordem directa, a mais natural. $O$ primeiro construiu a frase, partindo do que sentiu; o segundo, partindo apenas do que viu, e talvez pensou.

Tais observaçōes podem estar a reflectir respectivamente propriedades semânticas e comunicativas do verbo, segundo as quais o verbo reduzido ao seu lado semântico provoca a anteposição do sujeito. Ao contrário, o verbo com o valor comunicativo favorece a ordem VS.

Os exemplos com os verbos de entrada em cena mostram como o mesmo verbo pode aparecer com diversas construções, devido ao tipo de factor determinante em que se apresentam.

Quanto aos verbos existenciais, de uma maneira geral, podemos dizer que as construções existenciais são as que marcam a existência, o estado de ser de um argumento referencial. Por isso, aparecem em tais frases os verbos introdutórios, existenciais do tipo: existir, ser, haver. As construções com estes verbos tienen como misión el introducir un nuevo participante en el discurso (Cabeza Pereiro, 1997: 167), marcando o facto mais importante - a existência de um fenómeno. Não deve estranhar então que a forma há ocupa o lugar normalmente reservado ao sujeito da frase, por isso o sujeito perde algumas das suas propriedades, aproximando-se ao objecto da frase. Parece que o elemento nominal, detrás do verbo, não tem características plenas do sujeito regular.

Além disso, a análise de construções com verbos existenciais nas línguas como o português, o espanhol e o inglês levou à observação que o elemento nominal que segue o verbo existencial é com frequência indefinido. Não há frases do tipo:

9a. *Há o livro na mesa.

9b. *Há os livros na mesa.

Daí podemos tirar a conclusão que a informação contida no SN não é compartida pelo falante e ouvinte no acto de comunicação. Assim, entramos no nível da estrutura informativa da frase, e de tal forma podemos deduzir que o verbo transmite a informação suportadora que forma o ponto da partida para a informação nova contida pelo elemento nominal.

A ordenação informativa nas frases existenciais tem uma consequência importante na sua estrutura gramatical. A construção da frase existencial reflecte a tendência discursiva a iniciar a frase com a informação velha para introduzir a nova informação no final. Assim, na maioria das frases existenciais os locativos são 
definidos (conhecidos) e os sujeitos vêm indefinidos, como mostra o seguinte exemplo:

10. Na rua há carros.

locativo - existência - sujeito

Por outro lado, a explicação a respeito da anteposição dos verbos de reaç̧ão psicológica, será diferente. A sua frequente posição antes do sujeito pode explicarse pelo factor comunicativo. Assim, as frases com tais verbos são, muitas vezes, respostas às perguntas téticas do tipo Que se passa? Vejam-se os exemplos:

\section{1. -Que deseja?}

- Interessa-me este livro.

Embora a situação seja mais clara no caso dos enunciados téticos, a inversão não é sempre natural se acrescentamos outros constituintes à frase. Observam-se certas diferenças entre os níveis da aceitabilidade quando se destaca numa frase a dicotomia tema/rema:

12. Telefonou o João (tética).

12a. *Telefonou à Maria o Joāo.

12b. *Telefonou o João à Maria.

13. Telefonou o Joāo às cinco.

13a. *Telefonou às cinco o João.

13b. Às cinco o João telefonou (ênfase estilística).

13c. Às cinco telefonou o João (ênfase do elemento circunstancial).

Nos exemplos $12(\mathrm{a}, \mathrm{b})$ o acrescentamento do objecto indirecto causa o posicionamento do elemento temático João no final da frase, que torna a ordem menos natural. A estranha construção (13a) é o resultado da separação dos elementos temáticos pelo constituinte remático às cinco. Os últimos exemplos podem ser aceites por motivos de ênfase. A diferença de aceitabilidade sentida entre as frases parece então resultar da estrutura informativa da frase.

\subsection{AS PROPRIEDADES SINTÁCTICAS DO VERBO}

O verbo interessar-se, citado no ex. (11), que aparece no início da frase, além de mostrar o seu carácter semântico representa as propriedades sintácticas especiais. É um verbo inacusativo. Segundo M. Gawełko (1995: 186) os verbos existenciais e os da reacção psicológica, em especial inacusativos, apresentam ambientes propícios à ordem VS, enquanto outras classes de verbos (tais como de expressão, ou de comportamento) apresentam-se como contextos inibidores da posposição.

Do ponto de vista da sintáctica do verbo, a observação dos casos da inversão leva à conclusão que parece a mais evidente de todas - os verbos transitivos não 
ocorrem quase nunca antepostos ao sujeito, nem no português, nem no espanhol. Por outro lado, como afirma Delbecque, citada por Gawełko (1995: 183): en una construcción intransitiva es mayoritaria la posposición (do sujeito). Segundo os resultados de Gawełko (1995: 184), o número das inversões de verbos transitivos é $12,9 \%$ perante $21,9 \%$ de verbos intransitivos, em frases independentes. Esta proporção é diferente, e portanto, um pouco paradoxal, nas subordinadas, onde os verbos transitivos colocam-se antes do sujeito com mais frequência do que os intransitivos ( $20 \%$ perante $16,3 \%$ ). O facto pode-se explicar pelos factores estruturais - a maioria das inversões ocorrem nas relativas, nas quais o pronome relativo desempenha um papel de complemento ou atributo. O elemento nessa posição, leva então a função do sujeito e abre a posição ao verbo.

No que se refere à inversão no português e espanhol, segundo a observação de M. Gawełko (1996: 235), ela é mais frequente que no francês, e ainda mais frequente que no inglês. Isso pode explicar-se pelo carácter sintético e em resultado a maior liberdade da ordem de palavras, em comparação com o carácter analítico do inglês, que favorece os esquemas mais ou menos fixos. $O$ que se destaca no caso das línguas românicas é o grande número das inversões independentes, ou seja, não condicionadas pela presença dos esquemas construtivos fixos, que por sua natureza implicam ou obrigam à inversão.

O carácter livre e activo do português e espanhol reflete-se em la colocación muy frecuente del verbo al comienzo de la frase, en posición preferente (Criado de Val, 1962: 210), não tem de ser o verbo existencial ou de entrada em cena:

14a. Formam-se bolhas na água... (BGPC, 1998: 119)

14b. Fizeram a matricula todos os alunos que estavam no corredor.

Muitas vezes, a anteposição do advérbio vem com a inversão simultânea VS, que é em alguns casos obrigatória. Assim ocorre, por exemplo, com os verbos existenciais e de movimento e a posição inicial do advérbio não vai nivelar essa tendência, p. ex.:

15a. Cá vem o Marco.

15b. Alié o rio.

\section{PALAVRAS FINAIS}

Acreditamos, com este curto estudo, ter apresentado o conjunto das propriedades do verbo que conduzem à inversão. Entre as características do verbo analisadas podemos distinguir três níveis da análise - sintáctico, semântico e comunicativo-informativo.

No plano sintáctico verificamos o facto do carácter transitivo do verbo favorecer a ordem SV nas frases independentes. Por outro lado, nas subordinadas predomina a ordem VS. Esta estrutura pode explicar-se pelo factor gramatical. O prono- 
me relativo nas subordinadas tem a função de complemento ou de argumento e el constituyente de este tipo en posición inicial lleva consigo normalmente la posposición del sujeto (apud Gawełko, 1995: 185). Os verbos intransitivos em frases independentes tendem à posposição.

Por outro lado, a semântica do verbo influi à ordem. Observa-se que os verbos, chamados existenciais (existir, haver), os verbos de entrada em cena (aparecer, ocorrer) e alguns verbos de reaç̧ão psicológica (gostar, importar) caracterizam-se por uma anteposição frequente. Observa-se também certo cruzamento dos traços semânticos dos verbos e sujeitos. Os sujeitos indefinidos e não especificados mostram a tendência à posposição.

Do ponto de vista informativo, a ordem VS predomina nos enunciados téticos, quer dizer os enunciados que trazem integralmente uma informação nova. As frases deste tipo dão respostas às perguntas $O$ que há? ou $O$ que se passa? $\mathrm{O}$ verbo costuma transmitir a informação suportadora que forma o ponto da partida para a informação nova contida pelo elemento nominal. Como a informação nova situa-se normalmente no final da frase, o verbo aparece no início que resulta em inversão.

\section{REFERÊNCIAS BIBLIOGRÁFICAS}

Brito, A.,M., Duarte I., S., (1980/81), Condições sobre posposição do sujeito, Boletim de Filologia, XXVII, 197-247.

Cabeza Pereiro, C., (1997), Las completivas de sujeto en español, Universidade de Santiago de Compostela.

Criado de Val, M., (1962), Fisionomía del idioma español, sus caracteristicas comparadas con las del francés, italiano, portugués, inglés y alemán. Madrid.

Gawełko, M., (1995), Sobre el orden de palabras básico en español, Anuario de Lingúística Hispánica, XI, 183-192.

Gawelko, M., (1996), L'étude sur l'ordre des mots dans les langues romances, vol. 1. Lublin.

López Meir a ma, B., (1997), La posición del sujeto en la cláusula monoactancial en español, Servicio de Publicacións da Universidade de Santiago de Compostela. Santiago de Compostela. 